Science, Technology and Development 35 (2): 54-62, 2016

ISSN 0254-6418 / DOI: 10.3923/std.2016.54.62

(C) 2016 Pakistan Council for Science and Technology

\title{
A Review on Exploring the Weed Suppressing Characteristics of Arbuscular mycorrhizal Fungi for Enhanced Plant Yield and Productivity
}

\author{
${ }^{1}$ Muhammad Shakeel and ${ }^{2}$ Tabassum Yaseen \\ ${ }^{1}$ Department of Biotechnology, Bacha Khan University, Charsadda, Khyber Pakhtunkhwa, Pakistan \\ ${ }^{2}$ Department of Botany, Bacha Khan University, Charsadda, Khyber Pakhtunkhwa, Pakistan
}

\begin{abstract}
Weeds are plants, grown out of place, which compete with major crop plants for food, space and light, etc. Various physical, cultural, biological and chemical methods have been used for weed control but they have not been successful mainly, due to increased cost, labour and time. The application of herbicides for weed control has proven helpful but cannot be applied in case of organic farming, which is chemical-free-farming system. Biocontrol methods, utilizing biological organisms, have the potential to control weeds growth to a large extent with limited cost but it has not been well explored. In this method, soil microbes, such as rhizobacteria, pathogenic fungi and root symbiotic fungi, i.e., Arbuscular mycorrhizal (AM) fungi have not been widely used. Several studies have shown that AM fungi can inhibit weed growth and proliferation, though the exact mechanism as to how they interact with weed is not known. Reduced seed germination of weeds in the presence of exudates secreted by AM colonized plant roots, changes in relative abundance of mycotrophic (AM host) and non-mycotrophic (non-AM host) weeds species and reduction in weed biomass in response to AM fungi are a few mechanisms reported by various studies till date. The interaction of AM fungi with weeds is not always detrimental but can confer several advantages as discussed in this article. This review article highlights the potential of AM fungi in suppressing weeds growth and intensifies the need to study this mechanism at molecular level to efficiently employ it as weed control method.
\end{abstract}

Key words: Weeds, biocontrol, Arbuscular mycorrhizal fungi, enhanced yield and production

\section{INTRODUCTION}

Weeds can be defined as "undesirable plants grown unintentionally and compete with major crops for nutrients, space, light and other required conditions”. It causes significant loss to our major crops' yield and the loss has been estimated as 34\% every year (Oerke, 2006). According to another study, the potential yield loss due to weeds growth could range from $45-95 \%$, subject to various control methods (Ampong-Nyarko and de Datta, 1991). Although, the yield loss can be reduced to large extent, using agricultural practices or toxic chemicals, known as herbicides (Wyse, 1994), but these are expensive, not ecologically and environmentally safe and not always friendly to our major crops. They are also the potential contaminant if leached below ground water and may ultimately enter in our bodies through unfiltered drinking water. Another problem, associated with herbicides application, is that more than 200 weeds have shown strong resistance against most of the herbicides (Heap, 2015). It is because they can confer resistance against various modes of actions of herbicides. Controlling weeds with herbicide application cannot be accomplished in case of organic farming. It is a kind of farming, where no chemical is added for weed control or getting enhanced crop yield but mostly rely on natural plant material and cultural techniques without harming the environment (Basker, 1992). The good thing in using herbicides for weed control is that it has no negative effect on crop colonization by AM fungi that have widely been noticed in case of mechanical weed control methods presumably due to AM fungal hyphal damages (Brito et al., 2013).

Biocontrol method for weed control: Understanding the limitations and hazardous effects of herbicides, the potential of microorganisms for weed control may be exploited (Templeton et al., 1979; Wapshere, 1974). In biocontrol method, which is the application of biological organisms for controlling weeds growth and proliferation, microbes have been used as foliar pathogens. Unfortunately, in this method of weed control, soil microbes, such as, rhizobacteria, pathogenic fungi and root symbiont arbuscular mycorrhizal fungi, have not been exploited. Later studies reported that these microbes can affect growth and development of weeds directly or

Corresponding Author: Muhammad Shakeel, Department of Biotechnology, Bacha Khan University, Charsadda, Khyber Pakhtunkhwa, Pakistan 
indirectly, which show the potential of these microbes for weeds control (Boyetchko, 1996). Foliar pathogen application can only be successful, if these microbes come in contact with shoots (leaves or stem), which is a prerequisite for infection to occur. It may not be successful in case of weeds, where meri-stem is protected with leaf sheath and not possible for fungus to reach weed stem (Greaves and MacQueen, 1991). Considering this problem, efforts shall be directed towards soil and seed borne microbes. The obvious problem, related to soil microbes, is complexity in their inoculation and delivering techniques. Another complexity, associated with biocontrol of weeds, is choosing and screening of single plants for identifying potential microbe, which can reduce or inhibit weed growth. Such screening of single plants for potential microbes is time consuming, laborious and not natural (Boyetchko, 1996).

In addition to biocontrol of weeds, some tissue culture based practices utilizing cell and callus culture for monitoring rhizobacteria were established for biocontrol of weeds (Souissi and Kremer, 1994). Despite knowing the presence of diverse microorganism in soil rhizosphere and their potential as weed control, these microbes have often been ignored by earlier studies. Now, the need is to properly explore soil microbes, their community structure, evaluate different strains having potential for weed control and examine the ecology of rhizosphere and microbial community (Boyetchko, 1996; Corneo et al., 2013). The interaction of weeds and soil microbes has been studied both in vivo and in vitro using mostly bacteria and in a few cases arbuscular mycorrhizal fungi. These studies have shown that weeds affect soil microbial composition (Carson et al., 2007; Corneo et al., 2011). Similarly, some weeds have been reported to have its specific microbial community in the soil (Sarathchandra et al., 1997).

This review article focuses, how AM fungal colonization reduces the weed growth, is there any grading or differences in reducing weed growth if in association with single or combination of AM fungal species? Is there any increase or decrease in weed plants growth in the presence of a crop species?

Significance of the study: Various methods have been used for weed control, including physical, cultural, mechanical and chemical control methods. These weed control methods have not been successful, due to some limitations. Mechanical weed control methods can disturb soil microbial community composition/structure and may have negative effects on crop plants colonization by AM fungi presumably due to fungal hyphal damages. In addition to possible hazardous effects of chemical/herbicides application on soil microbes and vegetation, many weeds have shown strong resistance against many herbicides. This study emphasizes the need to manipulate the potential of soil and roots borne microbes, such as AM fungi for suppressing weed plants growth, which has not been noticed by earlier studies. This study also stresses on exploring the weed inhibiting mechanism of AM fungi on molecular level to enable them to be applied on large scale weed control programmes.

Arbuscular mycorrhizal fungi and weed control: Arbuscular mycorrhiza is mutualistic association between plants roots and fungi, in which both partners get benefit from each other. The plant hosts provide the fungus with carbohydrates and get many things in return, including enhanced nutrient uptake and tolerance against biotic and abiotic stress, such as drought, salinity and insects, etc. Arbuscular mycorrhizal (AM) fungi can colonize about $85-90 \%$ plants, the remaining $10-15 \%$ plants are mostly weeds (Jordan et al., 2000). These plants seem to have lost the ability to be colonized by AM fungi presumably by adapting themselves to a particular area and developing deep rooting system for the uptake of necessary nutrients from the soil (Brundrett, 2009; Wang and Qiu, 2006). AM fungi is one of the microbe which has been manipulated for this purpose (Cameron, 2010; Jordan et al., 2000), though not much is known as to how these fungi interact with weeds. One study (Jordan et al., 2000) demonstrates that these fungi may alter the nature and structure of weed communities presumably by altering the relative abundance of mycorrhizal and non-mycorrhizal plants. This study further illustrates that AM fungi do not always adversely affect weeds growth but interaction with weeds reduces the crop yield losses subjected to if weeds minimize their negative effects on crop plants and enhance their positivity towards improving crop yield, soil microbial community structure and soil properties. Cultural practices have been reported to affect the infectivity of these fungi under different cropping system, notably organic and conventional cropping system (Bilalis et al., 2011) (Table 1, 2). A meta-analysis study conducted recently has demonstrated the potential of AM fungi towards weeds growth suppression either directly or indirectly. They can either reduce weeds growth by directly suppressing its growth or by increasing the competitive effects of the major crop plant, i.e., increasing the nutrients uptake of the crop plant and depriving weeds plants from the essential nutrients, such as, $\mathrm{N}, \mathrm{P}$, etc. It was also suggested that the relationship of crop-weed-AM fungi should be properly investigated before employing these fungi in integrated weed management programme (Li et al., 2016). 
Sci. Technol. Dev., 35 (2): 54-62, 2016

\begin{tabular}{|c|c|c|c|c|c|c|}
\hline \multirow[b]{2}{*}{ Weed type } & \multicolumn{2}{|c|}{ Weed density (no. $\mathrm{m}^{-2}$ ) } & \multicolumn{2}{|c|}{ Weed biomass $\left(\mathrm{gm}^{-2}\right)$} & \multicolumn{2}{|c|}{ Weed N (\%) } \\
\hline & Org. & Con. & Org. & Con. & Org. & Con. \\
\hline \multicolumn{7}{|l|}{ Non-competitive } \\
\hline Anthemis arvensis & $4.7 \pm 0.46$ & $3.1 \pm 0.32$ & $14.6 \pm 1.12$ & $10.7 \pm 0.67$ & $4.54 \pm 0.21$ & $4.20 \pm 0.12$ \\
\hline Fumaria officinalis & $3.3 \pm 0.42$ & $2.8 \pm 0.34$ & $2.2 \pm 0.76$ & $3.5 \pm 0.87$ & $1.93 \pm 0.21$ & $1.24 \pm 0.19$ \\
\hline Lamium aplecicaule & $4.2 \pm 0.54$ & $4.7 \pm 0.65$ & $9.6 \pm 0.43$ & $9.1 \pm 0.61$ & $2.94 \pm 0.32$ & $2.38 \pm 0.12$ \\
\hline Lolium rigidum & $1.5 \pm 0.31$ & $1.3 \pm 0.45$ & $7.2 \pm 2.10$ & $5.2 \pm 1.78$ & $3.56 \pm 0.14$ & $2.92 \pm 0.32$ \\
\hline Stellaria media & $3.4 \pm 0.12$ & $3.2 \pm 0.41$ & $12.3 \pm 1.76$ & $10.2 \pm 1.54$ & $2.54 \pm 0.12$ & $2.59 \pm 0.32$ \\
\hline Veronica hederifolia & $2.2 \pm 0.39$ & $2.7 \pm 0.41$ & $8.8 \pm 0.98$ & $6.9 \pm 1.32$ & $4.27 \pm 0.31$ & $3.80 \pm 0.18$ \\
\hline Total $^{\mathrm{a}}$ & $19.3 \mathrm{a}$ & $17.8 \mathrm{a}$ & $54.1 \mathrm{a}$ & $44.5 \mathrm{a}$ & - & - \\
\hline \multicolumn{7}{|l|}{ Competitive } \\
\hline Avena sterillis & $7.2 \pm 1.05$ & $3.4 \pm 1.32$ & $14.5 \pm 0.61$ & $10.5 \pm 0.52$ & $4.06 \pm 0.45$ & $3.26 \pm 0.32$ \\
\hline Gallium aparine & $3.9 \pm 0.32$ & $2.9 \pm 0.45$ & $18.9 \pm 2.45$ & $8.9 \pm 3.21$ & $1.79 \pm 0.13$ & $1.29 \pm 0.18$ \\
\hline Lactuca serriola & $4.1 \pm 0.21$ & $4.2 \pm 0.48$ & $20.6 \pm 2.76$ & $11 \pm 1.78$ & $3.31 \pm 0.12$ & $2.99 \pm 0.09$ \\
\hline Picris echioides & $3.1 \pm 0.21$ & $1.9 \pm 0.89$ & $13.1 \pm 0.79$ & $7.4 \pm 1.49$ & $3.56 \pm 0.11$ & $3.15 \pm 0.14$ \\
\hline Plantago lanceolata & $3.9 \pm 0.63$ & $2.2 \pm 0.51$ & $18.8 \pm 1.83$ & $9.8 \pm 4.14$ & $3.66 \pm 0.32$ & $2.92 \pm 0.17$ \\
\hline Sonchus oleraceus & $3.3 \pm 0.32$ & $3 \pm 0.67$ & $24.3 \pm 3.65$ & $14.2 \pm 2.77$ & $2.78 \pm 0.45$ & $2.51 \pm 0.31$ \\
\hline Total & $25.5 \mathrm{a}$ & $17.6 \mathrm{~b}$ & 110.2 a & $61.8 \mathrm{~b}$ & - & - \\
\hline
\end{tabular}

Table 2: Correlation coefficients between various parameters of weeds (Bilalis et al., 2011)

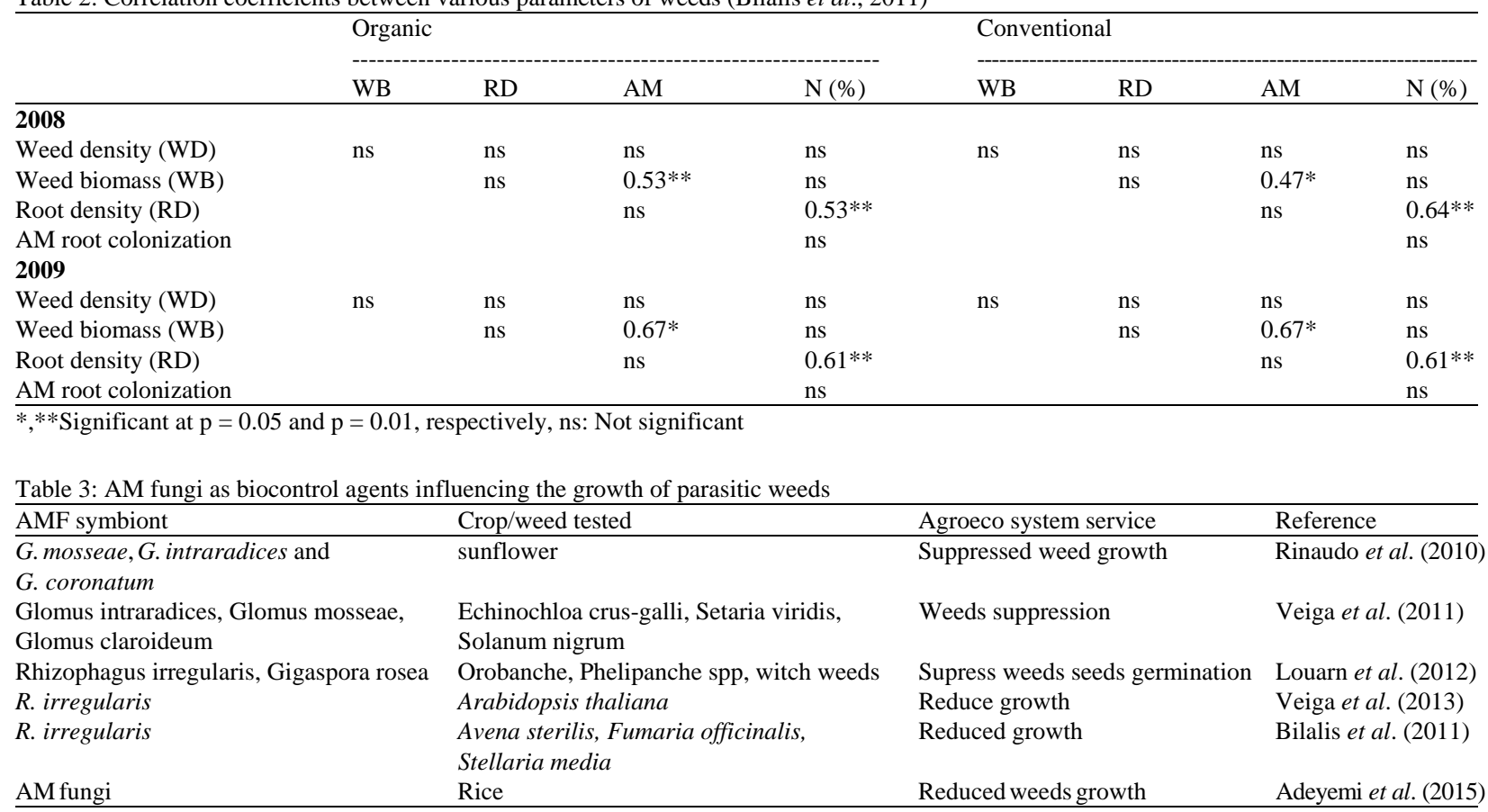

The AM fungi are believed to be ecologically important to several plants (mostly vascular) and they have the potential to alter the ecology of weeds species and can influence their growth without affecting the growth of major crop (Jordan et al., 2000). A study conducted to examine the effects of AM fungi on weeds growth showed that none of the weeds studied got positive growth response with AM fungal association. It has rather shown enhanced negative effects on weeds growth (Fig. 1). After studying the growth response, the authors also demonstrated that the presence of crops further increase the harmful effects of AM fungi on weeds growth (Rinaudo et al., 2010; Veiga et al., 2011;
Adeyemi et al., 2015). A similar experiment was performed by Rinaudo et al. (2010), where they grew a crop with six diverse weeds in the presence of AM fungi (Table 3). They reported $47 \%$ reduction in weed biomass from test where all weeds were grown together and 25\% reduction in weed biomass grown alone. Plant growth was promoted even in the presence of six strong competitors (weeds), which highlight the ability of Arbuscular mycorrhizal fungi to cope with diverse growing conditions.

Table 4 shows percentage of AM fungal colonization and plant density during 2011-2012. 
"Mono" indicates plant species cultivated alone, "mix" weeds grown in combination with maize. Monocultures and mixture of weeds inoculated with AM fungi (grey bars) or non-AM inoculated (black bars), Asterisks indicate significant differences in total biomass (AM colonized or non-AM). Numerical values (white) indicate mycorrhizal response in mono cultures or mixtures.

Variable effects of AM fungi on the mycorrhizal weeds species have been reported as some weeds species can be more strongly influenced than others. The adverse effects of AM fungi on weeds growth can vary with AM fungal strains and their relative abundance. More strong negative fungal effects on weeds (non-mycorrhizal) growth have been observed in the presence of AM fungal hyphae presumably due to secretion of some substances from the hyphae (Veiga, 2012), but no evidence has been presented so far to support this observation. One study (Fernandez-Aparicio et al., 2010) has demonstrated the reduced seed germination of Orobanche and Phelipanche under the influence of substances (exudates) secreted from two arbuscular mycorrhizal colonized leguminous plant roots (Fig. 1, 2). These exudates secreted from the root cells could be either of low molecular weight or variable molecular weight and also water soluble (Rovira et al., 1979). The presence of exudates influence microbes in the rhizosphere and have been reported to be the major carbon source for their growth (DeAngelis et al., 2009). Similar findings of reduced seed germination under the influence of AM fungi have also been demonstrated by several studies which show the potential of these fungi as key biocontrol agents (Louarn et al., 2012; Lendzemo et al., 2005, 2006;
Hearne, 2009; Gworgwor and Weber, 2003; Sui et al., 2014). Other studies (Malik and Charaya, 2012a, b) have reported 85 and $100 \%$ reduction in seed germination of
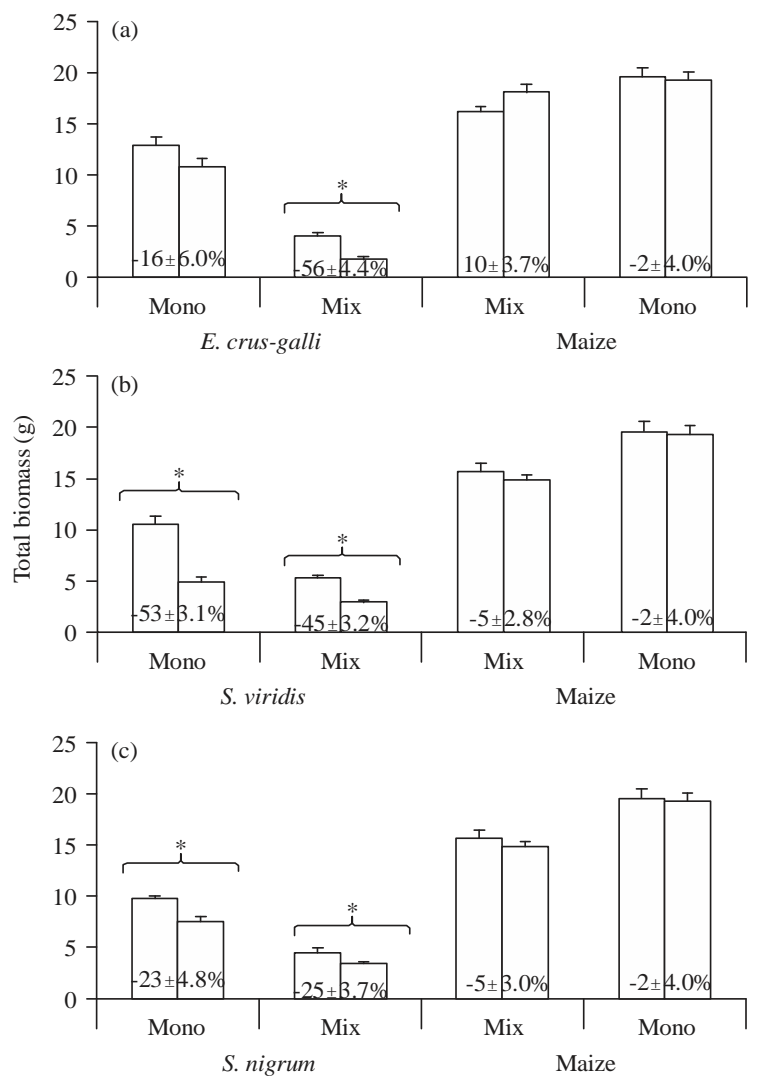

Fig. 1(a-c): Total biomass of three weeds (E. crus galli, S. viridis, S. nigrum) and maize (Veiga et al., 2011)

Table 4: Percentage of AM fungal colonization and its spore abundance affected by rice varieties and plant density during 2011-2012 (Adeyemi et al., 2015)

\begin{tabular}{|c|c|c|c|c|c|c|c|}
\hline \multirow[b]{2}{*}{ Variety (V) } & \multirow[b]{2}{*}{$\begin{array}{l}\text { Density (D) } \\
\text { (Plants ha }^{-1} \text { ) }\end{array}$} & \multicolumn{3}{|c|}{ AM spore abundance } & \multicolumn{3}{|c|}{ AM colonization } \\
\hline & & 2011 & 2012 & Mean & 2011 & 2012 & Mean \\
\hline \multirow[t]{4}{*}{ ITA 150} & 333,333 & 40.00 & 15.67 & 27.84 & 63.3 & 25.33 & 44.32 \\
\hline & 250,000 & 24.30 & 3.67 & 13.99 & 78.9 & 40.67 & 59.79 \\
\hline & 166,666 & 9.30 & 7.33 & 8.32 & 83.3 & 56.0 & 69.65 \\
\hline & Mean & 24.54 & 8.89 & 16.72 & 75.17 & 40.67 & 57.92 \\
\hline \multirow[t]{4}{*}{ NERICA II } & 333,333 & 28.70 & 6.33 & 17.52 & 60.00 & 41.33 & 50.67 \\
\hline & 250,000 & 35.30 & 5.0 & 20.15 & 51.1 & 32.00 & 41.55 \\
\hline & 166,666 & 29.70 & 7.33 & 18.52 & 61.1 & 54.67 & 57.89 \\
\hline & Mean & 31.23 & 6.22 & 18.73 & 57.4 & 42.67 & 50.04 \\
\hline \multirow[t]{4}{*}{ OFADA } & 333,333 & 31.70 & 13.33 & 22.52 & 76.70 & 42.67 & 59.69 \\
\hline & 250,000 & 17.00 & 9.00 & 13.00 & 62.20 & 44.00 & 53.1 \\
\hline & 166,666 & 20.00 & 31.33 & 25.67 & 81.10 & 33.33 & 57.22 \\
\hline & Mean & 22.9 & 17.89 & 20.40 & 73.33 & 40.00 & 56.67 \\
\hline \multicolumn{8}{|l|}{$\operatorname{SED}( \pm)$} \\
\hline Variety (Y) & & ns & * & & $7.06^{*}$ & ns & \\
\hline Density (D) & & ns & $*$ & & ns & ns & \\
\hline $\mathrm{V} \times \mathrm{D}$ & & ns & $*$ & & ns & ns & \\
\hline
\end{tabular}

ns: Not significant, $*$ Significant at $\mathrm{p}<0.05$ 
Sci. Technol. Dev., 35 (2): 54-62, 2016

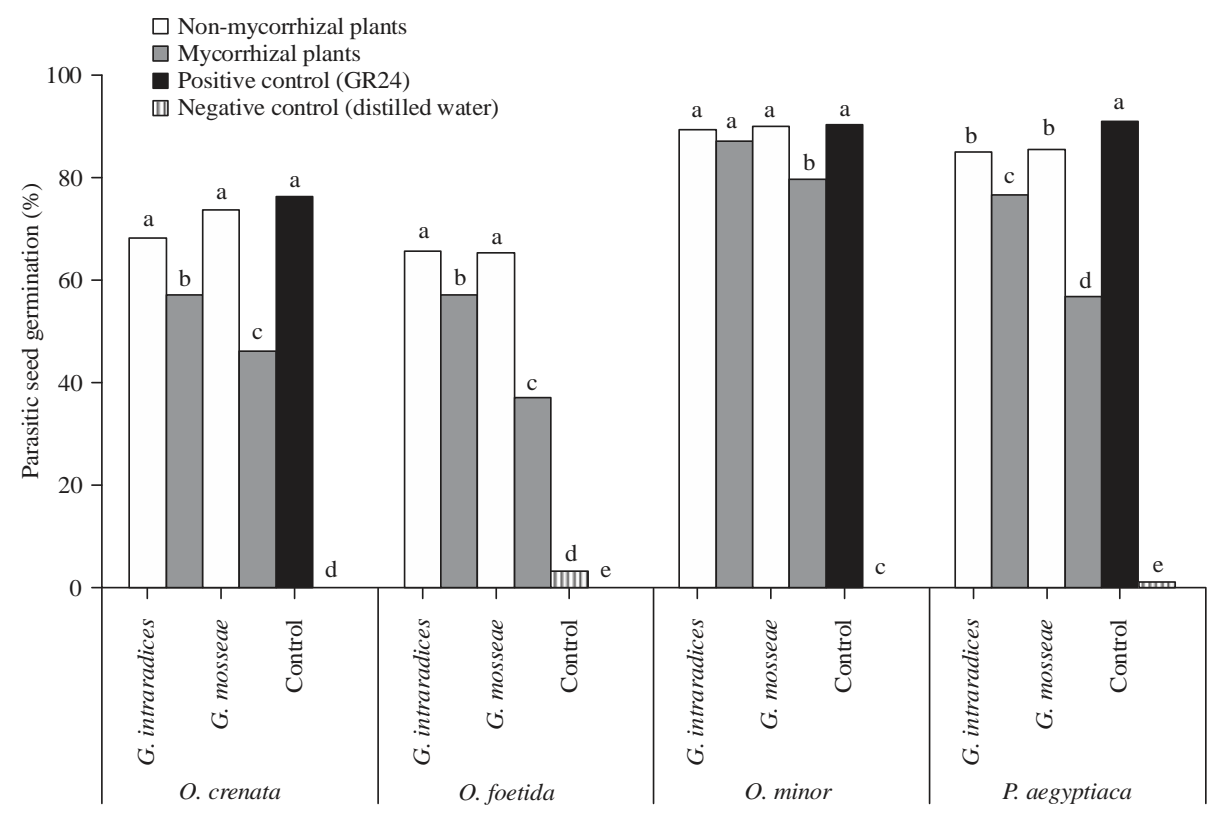

Fig. 2: Percent seeds germination of Orobanche crenata, O. foetida, O. minor and Phelipanche in response to plant root exudates which have been colonised by G. intraradices (G.i.) and G. mosseae (G.m.) and control plants (non-mycorrhizal), (taken from Fernandez-Aparicio et al., 2010)

parthenium (weed) in response to culture filtrate of verticillium species and Aspergillus flavus respectively. The reduction in seed germination was observed in late stages which is preferred in the earlier stages for efficient biocontrol of weeds. Sometimes, the effect of AM fungal treatments is less effective but the good thing is that it is normally long lasting in population (Malik, 2011).

Haustorium formation was found to have been inhibited in roots of Pedicularis tricolor after being inoculated with arbuscular mycorrhizal fungi, which shows the potential role of these fungi in the management of Pedicularis tricolor and Pedicularis rex (Li et al., 2013). However, the exact mechanism by which Haustorium formation has been suppressed by AM fungi is still unknown. Some studies have demonstrated dense and extensive growth of weed roots in crop area heavily infected with weeds. These roots have been observed to secrete some substances, which support weeds growth but reduce or inhibit crop growth. The effects of these root exudates on soil microbes have also been reported which support only specific soil dwelling microbes. AM fungi which promote the nutrient uptake of plants have been demonstrated to be adversely affected with the presence of these root exudates. Such adverse effects on AM fungi have mostly been reported from the herbicide resistant weeds, which disrupt the symbiotic relationship of plants and AM fungi (Kremer, 2014).
It has also been reported that AM fungi encourage the growth of mycorrhizal plants but inhibit the growth of non-mycorrhizal plants (Allen and Allen, 1984). One of the approaches used by AM fungi in inhibiting weed growth is changing the relative abundance of AM-colonized-weeds and non-AM-colonized weeds species in agroecosystem (Jordan et al., 2000). Plants species that do not form mutualistic relationship with AM fungi mostly belong to non-mycotrophic (not AM host) (Newman and Reddell, 1987) species. One reason for lack of mutualistic association in such cases may be incompatibility between plants and AM fungi, which may be indicated by browning of the plant roots, which would not have been seen if there is compatibility between plant roots and AM fungi. Plant roots after getting brown, cannot be infected by these invading fungi, the browning effect of the roots have been reported to be because of phenol accumulation in roots (Anderson, 1988).

The interaction of weed species with AM fungi is not always negative as some weed species have been reported to influence the diversity and abundance of agronomically important arbuscular mycorrhizal fungi (Vatovec et al., 2005). Such positive interaction of weeds and AM fungi has resulted in reduced losses of crop yield, arising from weeds and has shown positive effects of weeds on soil properties and community composition of soil microbes. Similarly a positive correlation has been observed 
between weeds dry weight and AMF percentage under the field condition. In such cases, the presence of a particular weed acts as determinants of a particular AM fungi (Kubota et al., 2015).

The AM fungi residing in the weeds free cultivated soil have been shown to be less diverse and efficient in supplying nutrients to the host plants as compared to soil containing weed species. They can also improve the mutualistic symbiosis with agronomically important crops (Feldmann and Boyle, 1999) which have resulted in enhanced AMF colonization of several crops (Kabir and Koide, 2000; Sorensen et al., 2005). Another study reporting the positive relationship of AM fungi and weeds biomass has demonstrated significant increase in weed biomass (Kubota et al., 2014). AM fungi can sometimes act as pathogen when soil conditions are not favourable, i.e., genes responsible for pathogenicity can be turned on under adverse soil condition, such as, phosphorous deficiency (Ryan et al., 2005). Similarly, not all weeds growth can be negatively affected by all AM fungi; therefore, they cannot be employed as efficient biocontrol system (Veiga et al., 2012; Sui et al., 2014). Some studies (Chen et al., 2004) have reported increased number of arbuscular mycorrhizal fungal spores when studied in association to large number of weeds species and enhanced positive effects of AM fungi on the growth and existence of Vincetoxicum rossicum species (Smith et al., 2008).

Limitations of AMF assisted weed biocontrol programme: Although AM fungi have played significant role in weed control and increased crop yield and productivity to a large extent but it has not achieved the target, due to following constraints:

- $\quad$ Several strains of AM fungi have been reported which respond differently (Bilalis et al., 2011) towards weed suppression. It is difficult to identify which fungal strain is efficient in suppressing weed growth due to lack of enough knowledge about genetics and genetic diversity of these fungi

- Some weed plants have been found to secrete exudates, which encourage weed growth but inhibit the growth of major crops. AM fungi have been reported to be adversely affected with the presence of these root exudates. Such adverse effects on AM fungi have mostly been reported from the herbicide resistant weeds which disturb the symbiotic relationship of plants and AM fungi

- The germination of some weed seeds have been inhibited by exudates secreted by AMF colonized plant roots. Reduction in weed seeds germination was observed at a later stage, which should ideally be in the first stage for efficient weed control programme

\section{CONCLUSION}

Various methods reported previously for weeds control have not been widely applied mainly, due to increase in cost, harmful effects and low efficacy. Biocontrol methods of weed control have not been well explored, which could significantly reduce the loss in crop yield, associated with the presence of diverse type of weeds plants. Among the soil microbes, AM fungi have the potential to inhibit or reduce weed plants growth, using a mechanism not been well explained till date. The potential of AM fungi for suppressing weeds growth can be exploited as one of the important biocontrol methods. According to a study conducted on weeds and AM fungi, the more adverse effects of these fungi on weeds growth can be observed in the presence of AM fungal hyphae due to unknown reasons. The interaction of AM fungi with weeds is not always harmful; some studies have shown positive effects of weeds on soil properties and community composition of soil microbes. Similarly, AM fungi, reported from weeds free soil, have shown to be less effective in supplying nutrients to its host plants than soil containing weeds. As, not all strains of AM fungi can inhibit weed plants growth, therefore, proper screening for the identification of efficient fungal strains is a prerequisite for a successful biocontrol programme.

As chemical control of weeds utilizing herbicides is expensive, ecologically and environmentally unsafe, efforts shall be directed towards biocontrol of weeds exploiting the potential of AM fungi for weed control. All potential strains of AM fungi should be isolated, cultured in vitro and tested for their ability for weed control programme. The potential of these fungi for weed control shall be monitored regularly in order to retain the efficient strains only. Only those fungal strains shall be included in weed control programme, which have been proved effective against most of the weed species. The exact mechanism is that how these fungi inhibit weed growth shall be studied at molecular level in order to identify the sites for improvement. Considering these recommendation, it is possible to suppress weeds growth to large extent and minimize the yield losses arising from weeds infestations in near future.

\section{REFERENCES}

Adeyemi, O.R., M.O. Atayese, M.O. Dare, O.S. Sakariyawo, S.O. Adigbo and T.O. Bakare, 2015. Weed control efficacy and Arbuscular mycorrhizal (AM) colonization of upland rice varieties as affected by population densities. J. Biol. Agric. Healthcare, 5: 178-185.

Allen, E.B. and M.F. Allen, 1984. Competition between plants of different successional stages: Mycorrhizae as regulators. Can. J. Bot., 62: 2625-2629. 
Ampong-Nyarko, K. and S.K. de Datta, 1991. A Handbook for Weed Control in Rice. International Rice Research Institute, Manila, Philippines, ISBN-13: 9789712200205, Pages: 113.

Anderson, A.J., 1988. Mycorrhizae-host specificity and recognition. Phytopathology, 78: 375-378.

Basker, D., 1992. Comparison of taste quality between organically and conventionally grown fruits and vegetables. Am. J. Altern. Agric., 7: 129-136.

Bilalis, D., A. Karkanis, A. Konstantas, S. Patsiali and V. Triantafyllidis, 2011. Arbuscular mycorrhizal fungi: A blessing or a curse for weed management in organic olive crops? Aust. J. Crop Sci., 5: 858-864.

Boyetchko, S.M., 1996. Impact of soil microorganisms on weed biology and ecology. Phytoprotection, 77: 41-56.

Brito, I., M. Carvalho and M.J. Goss, 2013. Soil and weed management for enhancing arbuscular mycorrhiza colonization of wheat. Soil Use Manage., 29: 540-546.

Brundrett, M.C., 2009. Mycorrhizal associations and other means of nutrition of vascular plants: Understanding the global diversity of host plants by resolving conflicting information and developing reliable means of diagnosis. Plant Soil, 320: 37-77.

Cameron, D.D., 2010. Arbuscular mycorrhizal fungi as (agro)ecosystem engineers. Plant Soil, 333: 1-5.

Carson, J.K., D. Rooney, D.B. Gleeson and N. Clipson, 2007. Altering the mineral composition of soil causes a shift in microbial community structure. FEMS Microbiol. Ecol., 61: 414-423.

Chen, X., J. Tang, Z. Fang and K. Shimizu, 2004. Effects of weed communities with various species numbers on soil features in a subtropical orchard ecosystem. Agric. Ecosyst. Environ., 102: 377-388.

Corneo, P.E., A. Pellegrini, C. Gessler and I. Pertot, 2011. Effect of weeds on microbial community in vineyards soil. IOBC/WPRS Bull., 71: 19-22.

Corneo, P.E., A. Pellegrini, L. Cappellin, M. Roncador, M. Chierici, C. Gessler and I. Pertot, 2013. Microbial community structure in vineyard soils across altitudinal gradients and in different seasons. FEMS Microbiol. Ecol., 84: 588-602.

DeAngelis, K.M., E.L. Brodie, T.Z. DeSantis, G.L. Andersen, S.E. Lindow and M.K. Firestone, 2009. Selective progressive response of soil microbial community to wild oat roots. ISME J., 3: 168-178.

Feldmann, F. and C. Boyle, 1999. Weed-mediated stability of arbuscular mycorrhizal effectiveness in maize mono-cultures. J. Applied Bot., 73: 1-5.
Fernandez-Aparicio, M., J.M. Garcia-Garrido, J.A. Ocampo and D. Rubiales, 2010. Colonisation of field pea roots by arbuscular mycorrhizal fungi reduces Orobanche and Phelipanche species seed germination. Weed Res., 50: 262-268.

Greaves, M.P. and M.D. MacQueen, 1991. Bioherbicides: Their Role in Tomorrow's Agriculture. In: Resistance'91: Achievements and Developments in Combating Pesticide Resistance, Denholm, I., A.L. Devonshire and D.W. Hollomon (Eds.). Elsevier Applied Science, London and New York, ISBN-13: 9781851668861, pp: 295-306.

Gworgwor, N.A. and H.C. Weber, 2003. Arbuscular mycorrhizal fungi-parasite-host interaction for the control of Striga hermonthica (Del.) Benth. in sorghum [Sorghum bicolor (L.) Moench]. Mycorrhiza, 13: 277-281.

Heap, I., 2015. The international survey of herbicide resistant weeds. http://www.weedscience.com/

Hearne, S.J., 2009. Control-the Striga conundrum. Pest Manage. Sci., 65: 603-614.

Jordan, N., J. Zhang and S. Huerd, 2000. Arbuscular-mycorrhizal fungi: Potential roles in weed management. Weed Res., 40: 397-410.

Kabir, Z. and R.T. Koide, 2000. The effect of dandelion or a cover crop on mycorrhiza inoculum potential, soil aggregation and yield of maize. Agric. Ecosyst. Environ., 78: 167-174.

Kremer, R.J., 2014. Environmental implications of herbicide resistance: Soil biology and ecology. Weed Sci., 62: 415-426.

Kubota, H., S. Quideau, P.J. Hucl and D.M. Spaner, 2014. Weeds promote the development of arbuscular mycorrhizal fungi in organic wheat fields. Proceedings of the 4th ISOFAR Scientific Conference at the Organic World Congress, October 13-15, 2014, Istanbul, Turkey, pp: 105-108.

Kubota, H., S.A. Quideau, P.J. Hucl and D.M. Spaner, 2015. The effect of weeds on soil arbuscular mycorrhizal fungi and agronomic traits in spring wheat (Triticum aestivum L.) under organic management in Canada. Can. J. Plant Sci., 95: 615-627.

Lendzemo, V.W., A. van Ast and T.W. Kuyper, 2006. Can arbuscular mycorrhizal fungi contribute to Striga management on cereals in Africa? Outlook Agric., 35: 307-311.

Lendzemo, V.W., T.W. Kuyper, M.J. Kropff and A.V. van Ast, 2005. Field inoculation with arbuscular mycorrhizal fungi reduces Striga hermonthica performance on cereal crops and has the potential to contribute to integrated Striga management. Field Crops Res., 91: 51-61. 
Li, A.R., K.Y. Guan, R. Stonor, S.E. Smith and F.A. Smith, 2013. Direct and indirect influences of arbuscular mycorrhizal fungi on phosphorus uptake by two root hemiparasitic Pedicularis species: Do the fungal partners matter at low colonization levels? Ann. Bot., 112: 1089-1098.

Li, M., N.R. Jordan, R.T. Koide, A.C. Yannarell and A.S. Davis, 2016. Meta-analysis of crop and weed growth responses to arbuscular mycorrhizal fungi: Implications for integrated weed management. Weed Sci., 64: 642-652.

Louarn, J., F. Carbonne, P. Delavault, G. Becard and S. Rochange, 2012. Reduced germination of Orobanche cumana seeds in the presence of arbuscular mycorrhizal fungi or their exudates. PLoS ONE, Vol. 7. 10.1371/journal.pone.0049273.

Malik, N. and M.U. Charaya, 2012a. Effect of spore suspension of Aspergillus flavus on seed germination of Parthenium hysterophorus L. Proceedings of the National Seminar on Advances in Biotechnology for Sustainable Global Environment, March 17-18, 2012, Department of Botany, D.N. College, Meerut, pp: 43.

Malik, N. and M.U. Charaya, 2012b. Effect of culture filtrate of Verticillium sp. on seed germination of Parthenium hysterophorus L. Proceedings of the National Biotechnology Conference on Leading Ideas and Future Encampment, April 28, 2012, Department of Biotechnology, I.T.S. Paramedical College, Muradnagar, Ghaziabad, pp: 9.

Malik, N., 2011. Studies on the bioherbicidal potential of rhizosphere microbiota of Parthenium hysterophorus L. Ph.D. Thesis, C.C.S. University, Meerut, India.

Newman, E.I. and P. Reddell, 1987. The distribution of mycorrhizas among families of vascular plants. New Phytol., 106: 745-751.

Oerke, E.C., 2006. Crop losses to pests. J. Agric. Sci., 144: 31-43.

Rinaudo, V., P. Barberi, M. Giovannetti and M.G.A. van der Heijden, 2010. Mycorrhizal fungi suppress aggressive agricultural weeds. Plant Soil, 333: 7-20.

Rovira, A.O., R.C. Foster and J.K. Martin, 1979. Note on Terminology: Origin, Nature and Nomenclature of the Organic Materials in the Rhizosphere. In: The Soil-Root Interface, Harley, J.L. and R.S. Russell (Eds.). Academic Press, New York, USA., ISBN: 978-0-12-325550-1, pp: 1-14.
Ryan, M.H., A.F. van Herwaarden, J.F. Angus and J.A. Kirkegaard, 2005. Reduced growth of autumn-sown wheat in a low-P soil is associated with high colonisation by arbuscular mycorrhizal fungi. Plant Soil, 270: 275-286.

Sarathchandra, S.U., G. Burch and N.R. Cox, 1997. Growth patterns of bacterial communities in the rhizoplane and rhizosphere of white clover (Trifolium repens L.) and perennial ryegrass (Lolium perenne L.) in long-term pasture. Applied Soil Ecol., 6: 293-299.

Smith, L.L., A. DiTommaso, J. Lehmann and S. Greipsson, 2008. Effects of arbuscular mycorrhizal fungi on the exotic invasive vine pale swallow-wort (Vincetoxicum rossicum). Invasive Plant Sci. Manage., 1: 142-152.

Sorensen, J.N., J. Larsen and I. Jakobsen, 2005. Mycorrhiza formation and nutrient concentration in leeks (Allium porrum) in relation to previous crop and cover crop management on high P soils. Plant Soil, 273: 101-114.

Souissi, T. and R.J. Kremer, 1994. Leafy spurge (Euphorbia esula) cell cultures for screening deleterious rhizobacteria. Weed Sci., 42: 310-315.

Sui, X.L., A.R. Li, Y. Chen, K.Y. Guan, L. Zhuo and Y.Y. Liu, 2014. Arbuscular mycorrhizal fungi: Potential biocontrol agents against the damaging root hemiparasite Pedicularis kansuensis? Mycorrhiza, 24: 187-195.

Templeton, G.E., D.O. TeBeest and R.J. Smith Jr., 1979. Biological weed control with mycoherbicides. Annu. Rev. Phytopathol., 17: 301-310.

Vatovec, C., N. Jordan and S. Huerd, 2005. Responsiveness of certain agronomic weed species to arbuscular mycorrhizal fungi. Renew. Agric. Food Syst., 20: 181-189.

Veiga, R., 2012. Biological weed control with soil fungi? Antagonistic effects of arbuscular mycorrhizal fungi on the growth of weeds. Ph.D. Thesis, Utrecht University, Netherlands.

Veiga, R.S., J. Jansa, E. Frossard and M.G. van der Heijden, 2011. Can arbuscular mycorrhizal fungi reduce the growth of agricultural weeds? PLoS ONE, Vol. 6. 10.1371/journal.pone.0027825

Veiga, R.S.L., A. Faccio, A. Genre, C.M.J. Pieterse, P. Bonfante and M.G.A. van der Heijden, 2013. Arbuscular mycorrhizal fungi reduce growth and infect roots of the non-host plant Arabidopsis thaliana. Plant Cell Environ., 36: 1926-1937. 
Veiga, R.S.L., K. Howard and M.G.A. van der Heijden, 2012. No evidence for allelopathic effects of arbuscular mycorrhizal fungi on the non-host plant Stellaria media. Plant Soil, 360: 319-331.

Wang, B. and Y.L. Qiu, 2006. Phylogenetic distribution and evolution of mycorrhizas in land plants. Mycorrhiza, 16: 299-363.
Wapshere, A.J., 1974. A strategy for evaluating the safety of organisms for biological weed control. Ann. Applied Biol., 77: 201-211.

Wyse, D.L., 1994. New technologies and approaches for weed management in sustainable agriculture systems. Weed Technol., 8: 403-407. 